\title{
Time Machines
}

\section{Dear Reader,}

personal interests and hobbies are as varied as people themselves. And that is surely true of all those who work in the automotive industry. But nevertheless, I have often noticed, as was the case at a recent meeting of the MTZ Scientific Advisory Board, that these people in particular share a passion. It began with a dialogue with the person sitting next to me, and then more and more people joined in. The conversation was about classic cars. It did not matter whether the persons were proud owners themselves or not. Old cars have a fascination that transcends generations and age groups. But why is it that people have such a passion for old things when so much progress has taken place in the meantime and cars have been constantly further developed? One reason may be that they can now perhaps fulfil dreams that they could not afford in their youth. But that alone would not explain why someone is interested in cars, tractors, motor bikes or even boats that are often older than they are.

When I try to explain why I am so passionate about classic cars, I can immediately think of several reasons. A classic car is not generally a vehicle for everyday use; it is no longer simply a commodity. Old bodywork, engines and interiors are often restored with meticulous attention to detail - and often at considerable cost - and are cherished and cared for. The finished products look "as good as new", even though they are still old. In a way, they become time machines that take us on a journey into the past that would not otherwise be possible. Anyone who drives a classic car will feel and experience at first hand what motoring was like all those years ago. And it is always wonderful to see what technical solutions were achieved even then, without the assistance of CAD etc. It can even teach us some lessons, too. After all, some of the old ideas - newly implemented with the aid of modern development and production technology - have now become state of the art again. We need only think of petrol direct injection or alternative combustion processes based on Atkinson or Miller cycles.

Best regards,

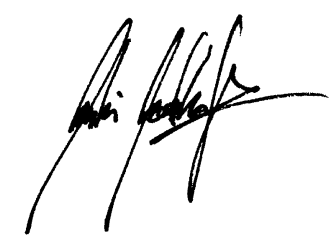

Dipl.-Journ. (FH) Martin Westerhoff Deputy Editor in Chief

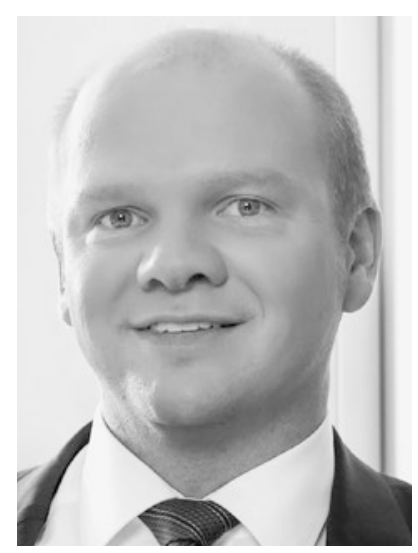

